\title{
Survey of Plants and Types of Horticultural Therapy Program in Hospitals - Focused on the Thesis from 1998 to 2016 -
}

\author{
Eun Jin Jang ${ }^{1}$, Suk Young Yun ${ }^{1 *}$, Byung Jin Choi ${ }^{1}$, and Na Hee Lee ${ }^{2}$ \\ ${ }^{1}$ Department of Horticulture, The Graduate School, Catholic Univ. of Daegu, Kyeongsan 38430, South Korea \\ ${ }^{2}$ Department of Horticultural Design, Daegu Future College, Kyeongsan 38607, South Korea
}

\begin{abstract}
As a result of inquiring into the analysis consequent on a symptom by research subject, it was found that there were 1 paper (1.5\%) which did research for the purpose of rehabilitation of the general public, 26 papers (38.8\%) targeting diagnosis-related groups (DRG), and 40 papers $(59.7 \%)$ targeting social consideration subject. Also, as a result of the inquiry about the frequency \& number of times of horticultural therapy program implementation, it was found that 49 papers (73.1\%) implemented one time a week, and 45 papers (67.2\%) were surveyed as the highest by conducting a total of 11 20 sessions of horticultural therapy programs, In the analysis of horticultural therapy activities by type, plant cultivation activity was found to be the most 506 times, accounting for $41.5 \%$, followed by 297 time crafts activity (24.4\%), 213 time floral decoration activity (17.5\%), and 203time others activities (16.7\%). In cultivation activity, soil-using cultivation activity $(25.1 \%)$ was found to be lower than the proportion (74.9\%) of soiless cultivation (16.4\%), crafts activity (24.4\%), floral decoration activity (17.5\%) and other activities (16.7\%). The most used plants in a restricted place like a hospital were found to be in the order of Hedera helix, Chamaedorea elegans, Succulent plant, Syngonium podophyllum, Neofinetia falcata HU, Hoya carnosa (L.f.) R.Br.), Rosmarinus officinalis, and Spathiphyllum spp.
\end{abstract}

Key words: crafts activity, diagnosis-related groups, floral decoration, soil-using cultivation

\section{I . Introduction}

Air pollution has been increasing due to rapid industrialization and urbanization, and issues like the spread of viruses, for instance, the outbreak of the Middle East Respiratory Syndrome Coronavirus (MERS CoV) in Korea in 2015, have been emerging as serious social issues (Shin, 2016). In addition, the increasing number of victims of toxic humidifier disinfectants in Korea has made people more concerned about and feel fear of air-borne diseases. In particular, those who live in urban areas stay for over $90 \%$ of their daily life indoors such as houses, offices, schools, hospitals, shops, restaurants, cars and subways, and thus their demand for a pleasant indoor environment has been every growing (Ecomedia, 2015).

Plants are known to reduce the level of fine dust in indoor air (Lohr and Pearson-mims, 1996) and they can give decorative effects as well as emotional stability to people as a living green

Received on March 10, 2017. Revised on March 27, 2017.

Accepted on April 18, 2017.

*Comesponding author: yune1004@cu.ac.kr construction material (Son, 2004). Furthermore, they are also known to be very effective to treat and rehabilitate the physical and mental health of humans (Tereshkovieh, 1973), and it was also reported that pain was relieved simply by touching plants (Lee et al., 2016). As non-threatening and non-discriminatory horticultural therapy using plants as a medium can also minimize patients' hostile response to therapy (Lewis, 1976), horticultural therapy has been widely used in nursing homes for elderly people and other rehabilitation facilities in Korea.

Patients who stayed in rooms with plants after surgery had the lower concentration of cortisol in their blood than those who stayed in rooms without plants (Jang, 2008). Horticultural activities using plants after the surgery of breast cancer reduced patients' physical and psychological anxiety, depression, stress, and had a positive impact on physiological conditions such as blood pressure and pulse (Shin, 2012).

Bacteria, however, exist in flower and plants in pots as normal strains, and sometimes fungi are produced from them. Since such fungi in air can become the source of infection for patients whose immune system is weak, provisions to ban 
flowers and plant pots are included in the instructions for inpatients distributed by general hospitals in Korea (Asan Medical Center, 2016; Severance Hospital, 2016).

Soil used in pots during horticultural therapy programs can contain pathogenic E. coli which poses a health risk to patients, and thus such activities are used only for few cases within hospitals. In this regard, it is necessary to come up with measures to expand the applications of horticultural therapy, and conduct studies on the safety of soil used in horticultural activities, the growth and development conditions of plants in sterilized soil which is relatively safe against pathogenic bacteria, and the species of plants that maximize the effects of treatment and rehabilitation.

In this study, among earlier studies on horticultural therapy, those that were conducted on inpatients in hospitals between 1998 and 2016 were analyzed to confirm that horticultural activities for inpatients have no risk of bacteria infection, and to provide reference data on the species of plants and indoor plant decoration techniques suitable for the purposes of treatment and rehabilitation within hospitals.

\section{Methods}

\section{Subjects}

In this study, key words including "horticultural treatment," "horticultural activity," "horticultural therapy," and "welfare horticulture" were searched on the Research Information Service System (www.riss.kr), and masters and doctoral theses that were conducted among inpatients in hospitals and published between 1998 and 2016 were collected. Among 78 theses, 10 theses unrelated to horticultural activities were excluded, and thus a total of 68 theses were analyzed in this study.

\section{Contents}

\section{1) Research participants and symptoms}

To systematically analyze the subjects, the collected theses were categorized based on the study of $\operatorname{Im}$ (2015) into "general group," "disease group," and "socially protected group." Those in the "general group" participated in horticultural programs for the purposes of reducing stress and preventing diseases, and those in the "disease group" were divided into 4 subgroups as follows: life-style disease, environmental disease, physical disease and mental disease sub-groups. Those in the "socially protected group" included elderly inpatients with geriatric diseases such as dementia.

2) Classification of horticultural therapy programs by types and analysis of plant species

The collected theses were also classified based on the number of sessions per week and the total number of sessions per program. The contents of activities were divided into four groups (planting, flower decoration, craft and other activities) and planting activities were in turn divided into those using soil and those not using soil. In addition, the species of plants used for the activities using soil were reviewed and their frequency was also analyzed.

\section{Analysis methods}

The collected theses that were conducted within hospitals were expressed as a percentage by categories, and their frequency was analyzed using the IBM SPSS19.0 Statistics program and a $\chi^{2}$ goodness-of-fit test was also conducted.

\section{Results and Discussion}

\section{Research participants and symptoms}

The theses that were conducted on horticultural therapy in hospitals between 1998 and 2016 were reviewed, and the share of the socially protected group was $59.7 \%$, followed by the disease group (38.8\%), and the general group (1.5\%) as shown in Table 1. These results indicated that horticultural therapy programs provided in hospitals were mainly designed to treat the diseases or reduce the symptoms of patients who had physical and mental diseases rather than for general people. The reason why the share of the theses on elderly patients with geriatric diseases such as dementia was high (59.7\%) can be attributable to the rising interest in demand for social welfare in the super-aged society and the increasing welfare rate for the elderly (MOHW, 2015). Horticultural activities are preferred by elderly people regardless of their race, age and gender 
Table 1. Classify for analysis of horticultural therapy.

\begin{tabular}{|c|c|c|c|c|}
\hline & Category & Thesis & Percent (\%) & $\chi^{2}(p)$ \\
\hline General population & Stress: Pregnant woman & 1 & 1.5 & \multirow{6}{*}{$\begin{array}{c}34.955^{* * *} \\
(.000)\end{array}$} \\
\hline \multirow[t]{4}{*}{ Group of disease } & Life habit disease: Hypertension & 1 & 1.5 & \\
\hline & Environmental disease & 0 & 0.0 & \\
\hline & Physical disease: Cancer, breast cancer, stroke & 8 & 11.9 & \\
\hline & Mental disease: Schizophrenia, mental illness, depressive disorder & 17 & 25.4 & \\
\hline Social objective & Old man problem: Demented elderly, geriatric patient & 60 & 59.7 & \\
\hline Total & & 67 & 100 & \\
\hline
\end{tabular}

$* * *$ Significant at $p<.001$.

(Wood, 2002), and they are known to be effective to prevent geriatric diseases such as dementia, and to improve the rehabilitation of chronic disease patients (Burgess, 1990; Relf, 1992; Hazen, 1997).

The results of analyzing the collected theses on inpatients in a limited environment like hospitals showed that there has been no study on children and patients with environmental diseases in the disease group as shown.

\section{Classification of horticultural therapy programs} by types and analysis of plant species

\section{1) The frequency and number of program sessions}

To analyze the frequency and number of program sessions, the collected theses were categorized based on the number of sessions per week and the total number of sessions. The number of theses of which sessions were conducted for less than 10 times in total was 7 (10.4\%), followed by those of which sessions were conducted for 11 20 times, 45 theses (67.2\%); those of which sessions were conducted for 21 30 times, 10 theses (14.9\%); those of which sessions were conducted for 31 40 times, 4 theses (6.0\%); and those of which sessions were conducted for over 40 times, 1 thesis (1.5\%).

In terms of the number of sessions per week, the number of theses of which sessions were conducted for once a week was $49(73.1 \%)$, followed by those of which sessions were conducted for twice a week, 14 theses (20.9\%); those of which sessions were conducted for 3 times a week, 2 these (3.0\%); and those of which sessions were conducted for 5 times a week, 2 these $(3.0 \%)$. There was no thesis of which session was conducted for 4 times a week (Table 2). The results did not
Table 2. Number of theses by total program and every week program.

\begin{tabular}{lcccc}
\hline \multicolumn{1}{c}{ Classification } & Item & Thesis & $\begin{array}{c}\text { Percent } \\
(\%)\end{array}$ & $\begin{array}{c}\chi^{2} \\
(\mathrm{p})\end{array}$ \\
\hline Total program & Under 10 & 7 & 10.4 & \\
(Number) & $11-20$ & 45 & 67.2 & \\
& $21-30$ & 10 & 14.9 & $96.507^{* * * *}$ \\
& $31-40$ & 4 & 6.0 & $(.000)$ \\
& Over 41 & 1 & 1.5 & \\
Every week program & 1 & 49 & 73.1 & \\
(Time) & 2 & 14 & 20.9 & \\
& 3 & 2 & 3.0 & $88.522 * * *$ \\
& 4 & 0 & 0.0 & $(.000)$ \\
& 5 & 2 & 3.0 & \\
\hline
\end{tabular}

$* * *$ Significant at $p<.001$.

coincide with the result of a study that programs conducted for twice a week were most effective (Kim, 2007), and this is attributable to the fact that the theses analyzed in this study were conducted among inpatients and activities were conducted regularly and continuously for the purpose of reducing their symptoms.

2) Analysis of horticultural therapy programs by types

Out of the horticultural therapy activities conduced in the collected theses, the number of planting activities was 506 (41.5\%); that of craft activities, 297 (24.4\%); that of flower decoration activities, 213 (17.5\%); and other activities, 203 $(16.7 \%)$ as shown in Figure 1.

Planting activities were divided into those using soil and those not using soil, and the results showed that the number of 
activities using soil was 306 (25.1\%), and that of activities not using soil was 200 (16.4\%). The activities using soil included dish garden, terrarium, seed sowing, transplanting, making culture soil and cuttage, and those not using soil included hydro-culture, making grass dolls, charcoal decoration, stone decoration, and raising green shoots and bean sprouts.

The share of craft activities was the second highest, and they included natural dying, making wreaths with artificial flowers, collages, herb soaps, potpourris, egg baskets, and decorations for aroma candles. Flower decoration activities include making flower baskets, making flower vases with vinyl, wrapping flowers, bouquets, corsages, and wreaths. Other activities included drawing flowers, making teas and foods, walking in forest, garden parties, natural observation, field trips, and

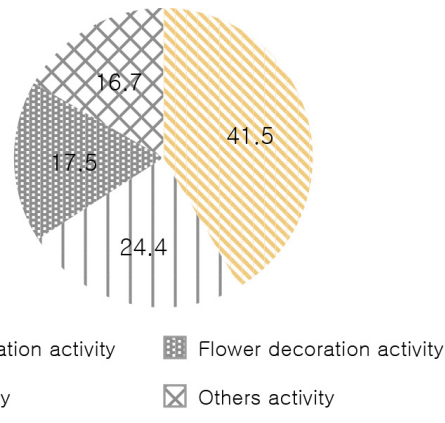

Fig. 1. Analysis of types of horticultural therapy programs. visiting exhibitions.

Kwack et al. (1999) found that activities of touching soil were effective to treat mental diseases, and Hyun et al. (2007) reported that green colors of plants stabilized the psychological and emotional states and that participants could achieve physical rehabilitation and psychological recovery by valuing the life of plants and doing reproductive activities even after horticultural therapy programs such as planting. The collected theses in this study, however, were conducted in a limited environment like hospitals where a risk of pathogenic bacteria has to be controlled, and thus the share of planting activities which required touching soil $(25.1 \%)$ was lower than the combined share $(74.9 \%)$ of planting activities which did not require touching soil (16.4\%), craft activities (24.4\%), flower decoration activities (17.5\%), and other activities (16.7\%).

\section{3) Analysis of plant species}

The species of plants used in activities of touching soil were reviewed, and a total of 68 species of plants were used for 278 times. Except vegetables, flower seeds, and transplanting, the most frequently used plant was Hedera helix, followed by Chamaedorea elegans, succulent plants, Syngonium podophyllum, Neofinetia falcata HU, Hoya carnosa (L.f.) R.Br., Rosmarinus officinalis, and Spathiphyllum spp. (Table 4).

Table 3. List of horticultural therapy programs.

\begin{tabular}{|c|c|c|c|c|}
\hline \multicolumn{2}{|c|}{ Category } & Horticultural activities & $\begin{array}{c}\text { Number of } \\
\text { program }(\%)\end{array}$ & $\begin{array}{l}\chi^{2} \\
(\mathrm{p})\end{array}$ \\
\hline \multirow[t]{2}{*}{$\begin{array}{l}\text { Plant cultivation } \\
\text { activity }\end{array}$} & $\begin{array}{l}\text { Touched the soil } \\
\text { activities }\end{array}$ & $\begin{array}{l}\text { Dish garden, terrarium, seeding, transplanting, hanging garden, } \\
\text { weeding, make culture soil, cuttage breeding }\end{array}$ & $306(25.1 \%)$ & \multirow{5}{*}{$\begin{array}{l}194.693 * * * \\
\quad(.000)\end{array}$} \\
\hline & $\begin{array}{l}\text { Not touched the } \\
\text { soil activities }\end{array}$ & $\begin{array}{l}\text { Hydro culture, grow bean sprouts, doll with grass seed, planting } \\
\text { orchid in charcoal, doll with potato, planting orchid in tree, } \\
\text { planting orchid in stone. }\end{array}$ & $200(16.4 \%)$ & \\
\hline Craft activity & & $\begin{array}{l}\text { Natural dyeing, wreath with artificial flower, collage, herb soap, } \\
\text { potpourri, paper flowers, making pressed flower, card, } \\
\text { calender, candle decoration, name card, making bunch of eggs, } \\
\text { making pot. }\end{array}$ & $297(24.4 \%)$ & \\
\hline $\begin{array}{l}\text { Flower decoration } \\
\text { activity }\end{array}$ & Only real flowers & $\begin{array}{l}\text { Flower packing with water bottle, flower arrangement, flower } \\
\text { basket, corsage, flower topiary, bouquet. }\end{array}$ & $213(17.5 \%)$ & \\
\hline \multicolumn{2}{|l|}{ Others activity } & $\begin{array}{l}\text { Garden party, visiting natural park, seal with potato, put out } \\
\text { watermelon seed, aroma massage, video \& slide, plant } \\
\text { explaining, tea, salad, jam, drawing flower, orientation, } \\
\text { exhibition }\end{array}$ & $203(16.7 \%)$ & \\
\hline Total & & & $1,219(100.0 \%)$ & \\
\hline
\end{tabular}

\footnotetext{
$* * *$ Significant at $p<.001$.
} 
Table 4. Kinds of plants used in cultivation with soil.

\begin{tabular}{llc}
\hline NO & \multicolumn{1}{c}{ Plant's name } & Total (\%) \\
\hline 1 & Heder helix & $16(5.8)$ \\
2 & Chamaedorea elegans & $15(5.4)$ \\
3 & Succulent plant & $15(5.4)$ \\
4 & Syngonium podophyllum & $14(5.0)$ \\
5 & Neofinetia falcata $\mathrm{HU}$ & $13(4.7)$ \\
6 & Hoya carnosa (L.f.) R.Br. & $11(4.0)$ \\
7 & Rosmarinus officinalis & $9(3.2)$ \\
8 & Spathiphyllum spp. & $9(3.2)$ \\
9 & Fittonia compacta & $8(2.9)$ \\
10 & Ardisia pusilla & $7(2.5)$ \\
11 & Euphorbia pulcherrima Willd ex Klotzsch & $7(2.5)$ \\
12 & Dracaena braunii & $6(2.2)$ \\
13 & Chrysanthemum morifolium & $6(2.2)$ \\
14 & Lavandula officnalis & $6(2.2)$ \\
15 & Trachelospermum asiaticum var. intermedium & $6(2.2)$ \\
\hline
\end{tabular}

Plants used in horticultural activities within hospitals are grown not only for ornamental purposes, but also for improved indoor environments and stable emotions (Wood et al., 1998). They also offer various benefits such as purifying air, controling temperature and humidity, generating anions, blocking noise, etc. (Lohr, 1992; Lohr et al., 1996; Son et al., 1997). In addition, Hedera helix, the most frequently used plant, is very easy to care for indoors, and grows very quickly, and thus participants can care for the plant easily and also see it grow for a short period of time. This seems to be effective to rehabilitate the physical and mental health of participants.

The original goal of horticultural therapy is to care for and grow living plants in person (Relf, 2008), and the most important aspect in it is soil. Many earlier studies found that activities of making soil even and touching soil are effective to treat mentally ill patients, and that green colors of leaves give humans psychological and emotional stability (Matsuo, 1996; Kwack et al., 1999; Yun, 2002; Do, 2007). As the results of these studies showed, soil is very important in plating activities of horticultural therapy. If it is possible to do plating activities and touch soil without a risk of bacteria infection within hospitals, the effects of horticultural therapy can be maximized.

In this regard, it is necessary to conduct follow-up studies as follows. First, it is necessary to test techniques of planting the most frequently used species under the same indoor environment of hospitals using sterilized soil, general soil for repotting, and hydro-culture techniques, and to test and analyze whether harmful microorganisms are reproduced near root zones over time. Second, it is also recommended to conduct horticultural therapy activities in hospital rooms by dividing participants into two groups: one using soil and the other not using soil. The concentration of hormones in their blood can be analyzed to identify correlations among soil, horticultural therapy activities, and patients.

\section{Conclusions}

Although provisions to ban flowers and plant pots are included in the instructions for inpatients distributed by general hospitals in Korea, horticultural therapy has been continuously used in several hospitals and nursing homes for elderly people for the purposes of rehabilitation and health improvement. Against this backdrop, this study reviewed a total of 68 theses on horticultural therapy that were conducted among inpatients in hospitals in Korea between 1998 and 2016. The collected theses were categorized based on the symptoms of participants, and the types of horticultural therapy programs, and the species of plants that were widely used in planting activities of using soil. In terms of the groups of participants, the number of theses conducted for the purpose of the rehabilitation of general people was 1 thesis (1.5\%); that of theses conducted for the disease group, 26 theses (38.8\%); and that of theses conducted for the socially protected group, 40 theses $(59.7 \%)$. The analysis results of the frequency and number of horticultural programs showed that the number of theses of which sessions were conducted for once a week was 49 theses $(73.1 \%)$, and the number of theses of which sessions were conducted for 11 20 times in total was 45 theses (67.2\%). The analysis results by the types of horticultural therapy activities showed that the number of planting activities was 506 times (41.5\%), followed by craft activities, 297 times (24.4\%); flower decoration activities, 213 times (17.5\%); and other activities, 203 times (16.7\%). The share of planting activities which required touching soil $(25.1 \%)$ was lower than the combined share $(74.9 \%)$ of planting activities which did not require touching soil (16.4\%), craft activities (24.4\%), flower decoration activities (17.5\%), 
and other activities (16.7\%). The most frequently used plant in activities in a limited environment like hospitals was Hedera helix, followed by Chamaedorea elegans, succulent plants, Syngonium podophyllum, Neofinetia falcata HU, Hoya carnosa (L.f.) R.Br., Rosmarinus officinalis, and Spathiphyllum spp.

\section{References}

Asan Medical Center. 2016. Medical guidance. Retrieved from http:// www.amc.seoul.kr/asan/hospitalizationtreatguide.visitGuide.sp

Burgess, C.W. 1989. Horticulture and its application to the institutionalized elderly. Act. Adapt. Aging 14(3):51-62.

Do, R.J. 2007. Application and effect of the horticultural therapy program for life quality improvement on elderly peoples in the health-longevity rural community. MS thesis, Seoul Natl. Univ., Seoul, Korea.

Ecomedia. 2015. Annual air pollution fatalities 2.8 million. Retrieved from http:// www.ecomedia.co.kr

Hazen, T.M. 1997. Horticultural therapy in the skilled nursing facility. Act. Adapt. Aging 22(1-2):39-60.

Hyun, J.S., E.A. Im, M.K. Cho, and K.C. Son. 2007. Effect of horticultural therapy on the improvement of self-esteem and sociality of the mentally retarded persons in the group home. MS Thesis, Konkuk Univ., Seoul, Korea.

Im, Y.S. 2015. Forest welfare policy status and development direction. In W.H. Lee, 2015 Spring Conference. Seoul Association for Public Administration. Daejeon, Korea. pp.109-152.

Jang, J.G. 2008. Effect of indoor plants in hospital rooms on the reducing of cortisol of inpatients. MS thesis, Gyeongsang Natl. Univ., Jinju, South Korea.

Kim, S.H. 2007. Meta-analysis for the effectiveness of researches related to horticultural therapy. MS thesis, Konkuk Univ., Seoul, South Korea.

Kwack, B.H., J.K. Suh, and H.R. Kwack. 1999. Studies desirable for revealing typical features of horticultural therapy. J. Korean Flower Res Soc. 8(1):23-29.

Lee, H.K., Y.K. Yoo, and I.K. Kim. 2016. Effect of plants in the threatment of pain. Korean J. Hortic. Sci. Technol. 34 (Suppl 1):51-52.

Lewis, C.A. 1976. People-plant interaction: Human perspectives in horticulture. HortScience 11:4-5.

Lohr, V.I. 1992. The contribution of interior plants to relative humidity in an office. Human benefits of plants. Portland, Oregon, USA. 117-119.

Lohr, V.I., C.H. Pearson-mims, and G.K. Goodwin. 1996. Interior plants may improve worker productivity and reduce stress in a windowless environment. J. Environ. Horti. 14:97-100.

Lohr, V.I. and C.H. Pearson-mins. 1996. Particulate matter accumulation on horizontal surfaces in interiors: Influence of foliage plants. Atmos. Environ. 30(14):2565-2568.

Matsuo, E. 1996. Sociohorticulure - A new field of horticulture and its present status in Europe, the U.S.A. and Japan. J. Kor. Soc. Hort. Sci. 37(1):171-185.

MOHW (Ministry of Health and Welfare), 2015. Assessment of Social Welfare Facilities in 2014.

Relf, P.D. 1992. The role of horticulture in human well-being and social development. T A National Symposium. Timber Press. Portland, Oregon, USA.

Relf, P.D. 2006. Historical perspective on theoretical models for research and program development in horticultural therapy. In XXVII International Horticultural Congress-IHC2006: International Symposium on Horticultural Practices and Therapy for Human 775 (pp. 79-91).

Severance Hospital. 2016. Medical guidance. Retrieved from http:// sev.iseverance.com/guidance/hospitalization/vist/

Shin, J.M. 2012. The effect of horticultural activity on psychological stability and the change of the blood pressure and pulse in women after breast cancer surgery. MS thesis, Catholic Univ. of Daegu, Daegu, Korea.

Shin, S.N. 2016. Research on smart accessory for the safe management of humidifier. MS thesis, Hongik Univ., Seoul, Korea.

Son, K.C., S.K. Park, H.O. Boo, K.Y. Paek, K.Y. Bae, S.H. Lee, and B.G. Huh. 1997. Horticultural therapy. Sewon Press, Seoul, Korea.

Son, K.C. 2004. Horticultural healing. Joongangsaenghwal Press, Seoul, Korea.

Tereshkovich, G. 1973. Horticultural therapy: A review. HortScience 8:460-461. (Abstr.)

Wood, F.G. 2002. Ethnic differences in exercise among adult with diabetes. West. J. Nurs. Res. 24(5):502-515.

Wood, R.A., R.L. Orwell, and M.D. Burchett. 1998. Living plants to improve indoor air quality. Kor. Soc. Plant, People, Environ. 1(1):121-130.

Yun, S.Y. 2002. Effect of horticultural therapy on the improvement of recognition ability and decrease of depression in the demented old adults. MS thesis, Catholic Univ. of Daegu, Daegu, South Korea. 